\title{
EQ-5D-5L utilities per health states in Spanish population with knee or hip osteoarthritis
}

\author{
Lidia García-Pérez ${ }^{1,2,3,45^{*}}$ ĐD, Vanesa Ramos-García ${ }^{1,2}$, Pedro Serrano-Aguilar ${ }^{2,3,5}$, José Luis Pais-Brito 6,7, \\ María Aciego de Mendoza ${ }^{6}$, Jesús Martín-Fernández ${ }^{3,8,9}$, Roberto García-Maroto ${ }^{10}$, Juan Carlos Arenaza ${ }^{3,11}$ and \\ Amaia Bilbao ${ }^{3,12}$
}

\begin{abstract}
Background: The objective of this study was to obtain utilities by means of EQ-5D-5L for different health states in patients with knee osteoarthritis (KOA) or hip osteoarthritis (HOA) in Spain, and to compare these values with those used in foreign studies with the aim of discussing their transferability for their use in economic evaluations conducted in Spain.

Methods: Primary study: Observational prospective study of KOA or HOA patients in Spain. Sociodemographic and clinical characteristics were collected to characterize the sample. Utilities were elicited using the EQ-5D-5L questionnaire. ANOVA and bivariable analyses were conducted to identify differences between health states. Literature review: Using the bibliographic databases NSH EED and CEA Registry, we conducted searches of modelbased cost utilities analyses of technologies in KOA or HOA patients. Health states and utilities were extracted and compared with values obtained from the Spanish sample.

Results: Three hundred ninety-seven subjects with KOA and 361 subjects with HOA were included, with average utilities of 0.544 and 0.520 , respectively. In both samples, differences were found in utilities according to level of pain, stiffness and physical function (WOMAC) and severity of symptoms (Oxford scales), so that the worst the symptoms, the lower the utilities. The utilities after surgery were higher than before surgery. Due to limitations from our study related to sample size and observational design, it was not possible to estimate utilities for approximately half the health states included in the published models because they were directly related to specific technologies. For almost $100 \%$ of health states of the selected studies we obtained very different utilities from those reported in the literature.

Conclusions: To our knowledge this is the first article with detailed utilities estimated using the EQ-5D-5L in Spain for $\mathrm{KOA}$ and HOA patients. In both populations, utilities are lower for worse health states in terms of level of pain, stiffness and physical function according to WOMAC, and according to the Oxford scales. Most utilities obtained from the Spanish sample are lower than those reported in the international literature. Further studies estimating utilities from local populations are required to avoid the use of foreign sources in economic evaluations.
\end{abstract}

Keywords: EQ-5D-5L, Health states, Hip osteoarthritis, Knee osteoarthritis, Utilities

\footnotetext{
* Correspondence: lidia.garciaperez@sescs.es

${ }^{1}$ Fundación Canaria de Investigación Sanitaria (FUNCANIS), Camino

Candelaria No 44, 1a planta. 38109 El Rosario, Santa Cruz de Tenerife, Spain

${ }^{2}$ Servicio de Evaluación del Servicio Canario de la Salud (SESCS), Camino

Candelaria No 44, 1 a planta. 38109 El Rosario, Santa Cruz de Tenerife, Spain

Full list of author information is available at the end of the article
}

(c) The Author(s). 2019 Open Access This article is distributed under the terms of the Creative Commons Attribution 4.0 International License (http://creativecommons.org/licenses/by/4.0/), which permits unrestricted use, distribution, and reproduction in any medium, provided you give appropriate credit to the original author(s) and the source, provide a link to the Creative Commons license, and indicate if changes were made. The Creative Commons Public Domain Dedication waiver (http://creativecommons.org/publicdomain/zero/1.0/) applies to the data made available in this article, unless otherwise stated. 


\section{Background}

Osteoarthritis causes pain and functional incapacity. In developed societies with a high life expectancy, the prevalence of knee osteoarthritis (KOA) and hip osteoarthritis (HOA) is high, 23.9 and $10.9 \%$, respectively [1]. Osteoarthritis entails a social and economic burden in terms of health-related quality of life (HRQoL) $[2,3]$ and cost of the disease [2, 4]. Estimated expenses for KOA or HOA are equal to $0.5 \%$ of Spain's GDP [5].

Health problems with such an impact on society and the existent technologies for those health problems deserve to be the focus of health technology assessment and economic evaluation specifically to inform the evidence-based decision making by health authorities. During an economic evaluation it is common to conduct cost-utility analysis (CUA), that is, a comparison of at least two alternatives in terms of costs and outcomes where the outcome measure is expressed as qualityadjusted life years (QALY). The adjustment of quantity of life for quality of life is attained by means of application of weightings that try to reflect the desirability of different states of health by individuals or society and that are denominated utilities or health state utilities $[6,7]$. For example, 1 year lived in perfect life (utility $=1$ ) implies 1 QALY, but 1 year lived in a less perfect situation (utility = 0.5 , for example) implies less than one QALY (0.5 QALYs in this case). The main advantage of using QALYs as a measurement is due to its potentiality to be used to compare different technologies and even different diseases [6]. Moreover, cost-effectiveness thresholds have been estimated and/or set up in different countries to be used as a limit to decide those technologies to be reimbursed or included in the health care systems based on their cost-effectiveness [8]. For example, in Spain the most recent estimated threshold is $25,000 € / \mathrm{QALY}$, so any new technology with an incremental cost-effectiveness ratio over this threshold should not be adopted according to this study [9].

The EQ-5D [10], a generic HRQoL questionnaire, is the tool most commonly used in Spain to measure utilities [11]. In its most current version, [12] the EQ-5D-5 L questionnaire consists of two sections: a visual analogue scale to evaluate HRQoL from 0 to 100 and a questionnaire comprised of 5 questions or dimensions (mobility, selfcare, performing of usual activities, pain/discomfort and anxiety/depression) with 5 response levels (from no problems to extreme problems). Using combinations of these five questions it can be obtained $3125\left(5^{5}\right)$ health states and a weighted health score denominated utility index associated with each health state. This index varies from 1 (perfect health) to negative values ( 0 being the value equivalent to death) because valuation studies have found that there are less preferred states than death by the general population. The social value set obtained from the general population in Spain for the EQ-5D-5L has recently been published [13]. A previous article has analyzed the psychometric properties of the EQ-5D-5 L in osteoarthritis patients in Spain [14]: reliability (Cronbach's alpha = 0.86 ), validity (Spearman's correlation coefficient of EQ5D-5 L index and WOMAC pain and function subscales: -0.688 and -0.782 , respectively) and responsiveness (floor and ceiling effects $<3 \%$ ).

In a systematic review of utilities obtained from the Spanish population [11] it was found that $94 \%$ of articles used the EQ-5D questionnaire and that health state utilities for a significant number of diseases are unknown. The highest number of utilities was collated in the hospital and specialized care settings whilst only $18 \%$ of utilities were collected in primary care [11]. This same review identified three primary papers reporting utility values obtained from the Spanish population with KOA or HOA [15-17]. The values varied from 0.2 in patients with total knee replacement (TKR) before surgery to 0.64 at 6 months from surgery [15].

The economic evaluation of technologies applied to osteoarthritis, be they surgical $[18,19]$, pharmacologic [20] or other interventions [21], is of interest for researchers, professionals and health policy decision makers [22]. In a systematic review of CUA performed in Spain [23] three studies that evaluated technologies in KOA or HOA patients were identified [24-26]. None of these studies used health state utilities obtained from the Spanish population, but from studies conducted in other countries.

The lack of transferability of economic evaluations between countries makes necessary to perform studies in the local population [27]. Moreover, utilities used in economic evaluations ideally would proceed from studies performed in the local population or countries with similar context although very often values from foreign populations found in a review of literature is the only available source $[7,28]$. The ultimate purpose of this study is determining the values of utilities for a broad variety of health states obtained from Spanish population with KOA or HOA with different level of severity and being treated in different health care settings so that they are usable for future economic evaluations in Spain. Consequently two aims were pursued: 1) obtaining health state utilities in patients with knee or hip osteoarthritis using an observational study performed in Spain, and 2) comparing these values with others obtained in international studies with the purpose of discussing the transferability of utilities in KOA and HOA subjects.

\section{Methods}

To achieve these two aims, first, data collected in a primary study with observational and prospective design were analyzed. Second, a review of health state utilities included in published economic evaluations was performed. 


\section{Primary study \\ Participants}

An opportunistic and consecutive sample was recruited between January and December 2015 by doctors in traumatology, rheumatology and primary care consultations from three different areas of Spain (Vizcaya, Madrid and Tenerife). To be included patients had to be adults (>18 years), diagnosed of $\mathrm{KOA}$ or $\mathrm{HOA}$ according to criteria of the American College of Rheumatology [29] independently of the severity of the disease, and agreed to participate after being informed. Excluded were all those patients who did not understand Spanish, did not know how to read or who suffered from diagnosed cognitive impairment.

Sample size was estimated to achieve other objectives pursued in the project that required more power (mapping between EQ-5D-5 L and clinical questionnaires) than the descriptive analysis presented here; more information elsewhere [14, 30, 31]. It was estimated that 360 KOA or HOA patients were necessary. Assuming a loss rate of $10 \%$ for incomplete data based on prior experiences and a $75 \%$ response rate, recruitment of 712 subjects was set as an aim. In the end we were able to recruit more than needed, 758 patients with complete baseline data. Subjects were included in the study after giving their informed consent. The study received approval by the Ethics Committees for Clinical Research from the three geographical areas.

\section{Variables}

Data were collected at the time of recruitment and at 6 months both by the clinician and the patient. Sociodemographic variables (age, sex, region of residency, education, marital status and work situation) and clinical variables: comorbidity measured using the Charlson Index [32], weight, height, body mass index (BMI), joints affected by arthrosis, time since diagnosis, treatments received (pharmacologic, surgery, rehabilitation and physiotherapy) and healthcare setting where the patient was recruited, were included. Selfperceived measures were: Oxford Knee Score (OKS) [33] or Oxford Hip Score (OHS) [34]; Western Ontario and McMaster Universities Osteoarthritis Index (WOMAC) [35]; and the EQ-5D-5 L questionnaire [12] applying the value set published in Spain [13].

The OKS and OHS instruments measure the severity of symptoms in patients with $\mathrm{KOA}$ and HOA, respectively $[33,34]$. They are comprised of 12 questions and the score varies from 0 to 48 where 0 is the worst and 48 the best such that patients can be classified into 4 groups: satisfactory joint function (40-48), mild to moderate arthritis (30-39), moderate to severe arthritis (20-29), severe arthritis (0-19) [36]. These questionnaires were recently validated in the Spanish population [30,31].
The WOMAC is a multidimensional scale comprised of 24 items that measures dimensions: pain (5 items), stiffness (2 items) and physical function (17 items) in osteoarthritis patients [35]. This study used the Likert version with 5 answer levels for each item, which represent different degrees of intensity (none, mild, moderate, severe or extreme) graded from 0 to 4 . This score is added and standardized from 0 to 100 such that the higher the score the worse the patient's condition. This questionnaire was validated in Spain for KOA and HOA patients [37].

\section{Statistical analysis}

Sample characteristics are reported as mean and standard deviation (SD) and frequencies and percentages for continuous and categorical variables, respectively. The proportion of patients by dimension and level of response in the EQ-5D-5 L questionnaire are presented. Subgroups were created using clinical baseline and selfreported information for the variables mentioned above (WOMAC, OKS, OHS, number of comorbidities, BMI, etc.). Although some of the subgroups are not necessarily associated to a health condition, such as age group, these subgroups are used for the estimation of the corresponding utilities and we call them indistinctly health states or subgroups. For those patients who underwent a surgical procedure during the 6 months follow-up health states are defined and utilities estimated using a followup questionnaire that included the same questions used for the baseline. In both cases the mean and SD for health state utilities are reported. Results were compared with normative values obtained from general population interviewed in the Spanish National Health Survey (20112012) [38]. We hypothesized that different (worse) health states mean different (lower) utilities. To identify statistically significant differences between subgroups, ANOVA and student $t$ analyses with multiple testing correction were performed (Bonferroni test when we assume population variances are equal after Levene's test or Tamhane's T2 in other cases). $P<0.05$ was considered statistically significant; $P<0.01$ for multiple comparisons. The program IBM SPSS Statistics 24.0.0.1 (Armonk, NY; IBM Corp) was used to perform the statistical analyses.

\section{Literature review}

A systematic search was performed in July 2017 in the NSH EED database (Center for Reviews and Dissemination, University of York). The search strategy is included as Additional file 1: Table S1. Reviewing the title and abstract, those economic evaluations based on models that evaluated technologies in KOA or HOA patients and that included QALYs among the outcome measures were selected. The CEA Registry (Cost-Effectiveness Analysis Registry) database was used [39] to extract health states and health state utilities included in these economic 
evaluations. The CEA Registry is a comprehensive database of $>7000$ cost-utility analyses from literature published in English around the world where utility values, health states and costs per QALY are collected [39]. In addition, papers selected were reviewed and information on the origin and kind of instrument used to obtain utilities was extracted.

Health states equivalent to those health states identified in the literature review were defined using our data, and utilities from our sample of Spanish patients were obtained according to the methodology reported above. An analysis of the utilities obtained with our sample was performed in comparison to utilities reported in the international literature. According to McClure et al., the minimally relevant difference in utilities for EQ-5D-5 L for Spain was estimated at 0.045 [40], whereby we assessed differences identified with this value.

\section{Results}

Statistical differences were found between the utility index for the sample with a diagnosis of $\mathrm{KOA}$ or $\mathrm{HOA}($ mean =
$0.533 ; N=750)$ and the normative value obtained for the Spanish general population (mean $=0.896 ; N=20,560$ ) $(P<0.0001)$. Differences were also found for men, women, and each age group except for the population older than 85 years $(P=0.630)$ (Additional file 1: Table S2).

\section{Results of the primary study}

Knee osteoarthritis: A total of 397 subjects were recruited with KOA (Table 1). Average age was 71.42 years (SD: 9.06) (range: 35-94) and 70\% were women. A total of $58 \%$ of the sample was recruited in primary care health centers, the remainder were recruited in hospital; $42 \%$ have arthrosis in both knees. Average scores of selfadministered questionnaires, WOMAC, OKS and EQ5D-5 L index were respectively, 49.63 (SD: 20.32), 21.96 (SD: 9.96), 0.544 (SD: 0.271).

The most common state of health (32331) corresponds to a patient with moderate problems in the dimensions mobility, daily activities and pain/discomfort, slight problems in self-care and not anxious or depressed. The second most common state of health (11121) corresponds to

Table 1 Characteristics of the samples with knee and hip osteoarthritis

\begin{tabular}{|c|c|c|c|c|c|c|c|c|c|}
\hline \multirow[t]{2}{*}{ Characteristic } & & \multicolumn{4}{|c|}{ Knee osteoarthritis } & \multicolumn{4}{|c|}{ Hip osteoarthritis } \\
\hline & & $\mathrm{N}$ & $\%$ & Mean & SD & $\mathrm{N}$ & $\%$ & Mean & SD \\
\hline \multicolumn{2}{|l|}{ Age (years) } & 397 & & 71.42 & 9.06 & 361 & & 67.88 & 11.67 \\
\hline \multirow[t]{2}{*}{ Sex } & Women & 277 & 70 & & & 192 & 53 & & \\
\hline & Men & 120 & 30 & & & 169 & 47 & & \\
\hline \multirow[t]{3}{*}{ Region } & Basque Country & 158 & 40 & & & 157 & 44 & & \\
\hline & Canary Islands & 81 & 20 & & & 80 & 22 & & \\
\hline & Madrid & 158 & 40 & & & 124 & 34 & & \\
\hline \multirow[t]{2}{*}{ Type of health center } & Primary healthcare center & 230 & 58 & & & 204 & 57 & & \\
\hline & Hospital & 167 & 42 & & & 157 & 44 & & \\
\hline \multirow[t]{3}{*}{ Joint with osteoarthritis } & Right & 110 & 28 & & & 138 & 38 & & \\
\hline & Left & 119 & 30 & & & 121 & 34 & & \\
\hline & Both joints & 168 & 42 & & & 102 & 28 & & \\
\hline \multicolumn{2}{|l|}{ BMI } & 389 & & 29.67 & 4.87 & 355 & & 28.16 & 4.57 \\
\hline \multicolumn{2}{|l|}{ Weight (kg) } & 395 & & 77.67 & 14.00 & 357 & & 76.47 & 15.04 \\
\hline \multicolumn{2}{|l|}{ Height (cm) } & 389 & & 161.93 & 8.57 & 356 & & 164.57 & 8.84 \\
\hline \multicolumn{2}{|c|}{ Charlson Index (No of comorbidities) } & 395 & & 0.78 & 1.14 & 361 & & 0.84 & 1.31 \\
\hline \multicolumn{2}{|c|}{ WOMAC - Pain score $(0-100)$} & 396 & & 47.00 & 20.49 & 360 & & 45.81 & 22.77 \\
\hline \multicolumn{2}{|c|}{ WOMAC - Stiffness score (0-100) } & 396 & & 46.81 & 25.42 & 360 & & 48.26 & 26.05 \\
\hline \multicolumn{2}{|c|}{ WOMAC - Physical function score (0-100) } & 397 & & 51.08 & 20.95 & 360 & & 52.43 & 23.05 \\
\hline \multicolumn{2}{|l|}{ WOMAC Score (0-100) } & 397 & & 49.63 & 20.32 & 359 & & 50.69 & 22.25 \\
\hline \multicolumn{2}{|l|}{ Oxford Scale Score (0-48) } & 395 & & 21.96 & 9.96 & 359 & & 22.84 & 10.62 \\
\hline \multicolumn{2}{|l|}{ EQ-5D-5 L Index } & 393 & & 0.544 & 0.271 & 357 & & 0.520 & 0.304 \\
\hline \multicolumn{2}{|l|}{ EQ-5D VAS (0-100) } & 390 & & 57.36 & 21.55 & 359 & & 54.47 & 22.27 \\
\hline
\end{tabular}

BMI Body mass index, SD Standard deviation, WOMAC Western Ontario and McMaster Universities Osteoarthritis Index

WOMAC: 0, worst; 100 , best

Oxford Scale Score: 0, worst; 48, best (severity of arthritis)

EQ-5D-5 L Index: 0, death; 1, perfect health 
a patient with slight pain or discomfort and no problems in the other dimensions (Additional file 1: Table S3). By dimensions the moderate level was the most common in mobility (45.8\%), usual activities (36.3\%) and pain/discomfort (38.5\%). Self-care level 1 (no problems) and level 3 (moderate) were reported equally (32\%). For anxiety/depression $43.3 \%$ of the sample reported not having any problems. Levels 4 and 5 (severe and extreme) were reported less commonly although $30.2 \%$ of patients reported having severe pain or discomfort and $24.4 \%$ reported severe problems in mobility (Table 2). Among the 18 patients that reported negative utility values, the most common health state was 44444 (4 patients), that is, with severe problems in the five dimensions.

Table 3 shows the health state utilities for different population subgroups. No statistically significant differences were detected between groups according to age, sex, region of Spain, joint with osteoarthritis (right or left), time since diagnosis (years), with or without prosthesis in the other joint and number of comorbidities. Differences identified between BMI categories $(P=0.029$; ANOVA $)$ disappeared when multiple comparison tests were conducted. Regarding clinical questionnaires (WOMAC, OKS), differences were found between all subgroups (the less clinical problems, the higher utilities) except for those two with less joint stiffness according to WOMAC ( $P=0.389$; Tamhane's T2). There was no difference between receiving and not receiving any pharmacologic treatment $(P=0.321)$, although patients taking opioid pain medication had significantly lower utilities than the whole sample $(P=0.005)$. During the 6-month follow up, 65 people out of 92 waiting for a prosthesis had had a TKR. There was an increase in the utility index after the TKR $(P<0.0001)$.

Hip osteoarthritis: A total of 361 subjects were recruited with HOA (Table 1). Average age was 67.88 years (SD: 11.67) (range: 36-89) and 53\% were women. A total of $57 \%$ of the sample was recruited in primary

Table 2 Percentage of patients with knee osteoarthritis reporting levels within EQ-5D-5 L dimensions

\begin{tabular}{|c|c|c|c|c|c|c|}
\hline Group & Dimension & Level 1 & Level 2 & Level 3 & Level 4 & Level 5 \\
\hline \multirow{5}{*}{$\begin{array}{l}\text { The whole sample } \\
(N=397)\end{array}$} & Mobility & 11.8 & 16.6 & 45.8 & 24.4 & 1.3 \\
\hline & Self-care & 32.0 & 27.0 & 32.0 & 8.8 & 0 \\
\hline & Usual activities & 16.6 & 26.7 & 36.3 & 15.9 & 4.3 \\
\hline & Pain/Discomfort & 4.0 & 23.2 & 38.5 & 30.2 & 4.0 \\
\hline & Anxiety/Depression & 43.3 & 24.2 & 18.1 & 10.8 & 2.5 \\
\hline \multirow{5}{*}{$\begin{array}{l}\text { OKS }- \text { severe } \\
(N=168)\end{array}$} & Mobility & 2.4 & 7.1 & 36.9 & 50.6 & 3.0 \\
\hline & Self-care & 10.1 & 18.5 & 51.8 & 19.6 & 0 \\
\hline & Usual activities & 2.4 & 10.1 & 44.6 & 33.9 & 8.9 \\
\hline & Pain/Discomfort & 1.2 & 3.0 & 33.9 & 52.4 & 9.5 \\
\hline & Anxiety/Depression & 28.0 & 23.2 & 25.6 & 17.9 & 5.4 \\
\hline \multirow{5}{*}{$\begin{array}{l}\text { OKS - moderate to severe } \\
(N=128)\end{array}$} & Mobility & 5.5 & 17.2 & 69.5 & 7.8 & 0 \\
\hline & Self-care & 28.1 & 43.0 & 27.3 & 1.6 & 0 \\
\hline & Usual activities & 10.9 & 36.7 & 46.1 & 4.7 & 1.6 \\
\hline & Pain/Discomfort & 0.8 & 23.4 & 51.6 & 24.2 & 0 \\
\hline & Anxiety/Depression & 44.5 & 25.8 & 20.3 & 9.4 & 0 \\
\hline \multirow{5}{*}{$\begin{array}{l}\text { OKS - mild to moderate } \\
(N=74)\end{array}$} & Mobility & 29.7 & 35.1 & 35.1 & 0 & 0 \\
\hline & Self-care & 68.9 & 28.4 & 2.7 & 0 & 0 \\
\hline & Usual activities & 39.2 & 51.4 & 9.5 & 0 & 0 \\
\hline & Pain/Discomfort & 10.8 & 55.4 & 32.4 & 1.4 & 0 \\
\hline & Anxiety/Depression & 67.6 & 27.0 & 2.7 & 1.4 & 1.4 \\
\hline \multirow{5}{*}{$\begin{array}{l}\text { OKS - satisfactory joint function } \\
(N=21)\end{array}$} & Mobility & 66.7 & 19.0 & 14.3 & 0 & 0 \\
\hline & Self-care & 100 & 0 & 0 & 0 & 0 \\
\hline & Usual activities & 85.7 & 4.8 & 9.5 & 0 & 0 \\
\hline & Pain/Discomfort & 19.0 & 66.7 & 14.3 & 0 & 0 \\
\hline & Anxiety/Depression & 81.0 & 14.3 & 4.8 & 0 & 0 \\
\hline
\end{tabular}

Level 1: indicating no problem; Level 2: indicating slight problems; Level 3: indicating moderate problems; Level 4: indicating severe problems; Level 5: indicating extreme problems

Highest frequencies are highlighted in bold letters 
Table 3 Utility weights (EQ-5D-5 L Index) per subgroup in patients with knee osteoarthritis

\begin{tabular}{|c|c|c|c|c|c|}
\hline Subgroup & & $\mathrm{N}$ & Mean & SD & $P$-value \\
\hline \multirow[t]{6}{*}{ Age groups (years) } & $<45$ & 1 & & & 0.746 \\
\hline & $45-54.99$ & 17 & 0.516 & 0.302 & \\
\hline & $55-64.99$ & 71 & 0.540 & 0.269 & \\
\hline & $65-74.99$ & 143 & 0.564 & 0.279 & \\
\hline & $75-84.99$ & 143 & 0.523 & 0.264 & \\
\hline & $\geq 85$ & 18 & 0.589 & 0.258 & \\
\hline \multirow[t]{2}{*}{ Gender } & Women & 275 & 0.528 & 0.269 & 0.079 \\
\hline & Men & 118 & 0.581 & 0.274 & \\
\hline \multirow[t]{3}{*}{ Region } & Basque Country & 154 & 0.503 & 0.570 & 0.053 \\
\hline & Madrid & 158 & 0.572 & 0.252 & \\
\hline & Canary Islands & 81 & 0.568 & 0.270 & \\
\hline \multirow[t]{5}{*}{ BMI categories } & Underweight $^{a}$ & 0 & - & - & 0.029 \\
\hline & Normal ${ }^{b}$ & 61 & 0.590 & 0.214 & \\
\hline & Overweight $^{c}$ & 154 & 0.577 & 0.261 & \\
\hline & Obesity $^{d}$ & 161 & 0.500 & 0.299 & \\
\hline & Morbid obesity ${ }^{e}$ & 10 & 0.465 & 0.215 & \\
\hline \multirow[t]{3}{*}{ Joint with osteoarthritis } & Right knee & 109 & 0.559 & 0.261 & 0.752 \\
\hline & Left knee & 117 & 0.546 & 0.259 & \\
\hline & Both knees & 167 & 0.533 & 0.287 & \\
\hline \multirow[t]{5}{*}{ Time since osteoarthritis diagnosis (years) } & $<1$ & 62 & 0.602 & 0.245 & 0.188 \\
\hline & 1 to $<5$ & 181 & 0.547 & 0.269 & \\
\hline & 5 to $<10$ & 93 & 0.536 & 0.270 & \\
\hline & 10 to $<15$ & 35 & 0.466 & 0.307 & \\
\hline & $\geq 15$ & 21 & 0.513 & 0.297 & \\
\hline \multirow[t]{2}{*}{ Contralateral knee } & Without prosthesis in the other knee & 314 & 0.546 & 0.275 & 0.986 \\
\hline & With prosthesis in the other knee & 78 & 0.545 & 0.250 & \\
\hline \multirow[t]{4}{*}{ Other joints } & Hip osteoarthritis & 53 & 0.519 & 0.312 & 0.101 \\
\hline & No hip osteoarthritis & 339 & 0.549 & 0.265 & \\
\hline & Osteoarthritis in other joints & 228 & 0.535 & 0.273 & 0.813 \\
\hline & No osteoarthritis in other joints & 164 & 0.558 & 0.269 & \\
\hline \multirow[t]{5}{*}{ Number of comorbidities (Charlson Index) } & No comorbidity & 215 & 0.572 & 0.257 & 0.149 \\
\hline & 1 comorbidity & 104 & 0.523 & 0.282 & \\
\hline & 2 comorbidities & 40 & 0.504 & 0.301 & \\
\hline & 3 comorbidities & 18 & 0.435 & 0.279 & \\
\hline & $\geq 4$ comorbidities & 14 & 0.522 & 0.282 & \\
\hline \multirow[t]{9}{*}{ WOMAC } & Pain score 0 to $<25^{\mathrm{a}}$ & 42 & $0.783^{\mathrm{bcd}}$ & 0.187 & $<0.0001$ \\
\hline & Pain score 25 to $<50^{b}$ & 163 & $0.648^{\text {acd }}$ & 0.186 & \\
\hline & Pain score 50 to $<75^{c}$ & 139 & $0.450^{\mathrm{abd}}$ & 0.248 & \\
\hline & Pain score 75 to $100^{d}$ & 48 & $0.252^{\mathrm{abc}}$ & 0.283 & \\
\hline & Stiffness score 0 to $<25^{a}$ & 44 & $0.716^{\mathrm{cd}}$ & 0.207 & $<0.0001$ \\
\hline & Stiffness score 25 to $<50^{b}$ & 134 & $0.652^{c d}$ & 0.215 & \\
\hline & Stiffness score 50 to $<75^{c}$ & 127 & $0.506^{\mathrm{abd}}$ & 0.250 & \\
\hline & Stiffness score 75 to $100^{d}$ & 87 & $0.347^{\mathrm{abc}}$ & 0.277 & \\
\hline & Physical function score 0 to $<25^{a}$ & 41 & $0.845^{\mathrm{bcd}}$ & 0.113 & $<0.0001$ \\
\hline
\end{tabular}


Table 3 Utility weights (EQ-5D-5 L Index) per subgroup in patients with knee osteoarthritis (Continued)

\begin{tabular}{|c|c|c|c|c|c|}
\hline Subgroup & & $\mathrm{N}$ & Mean & SD & $P$-value \\
\hline & Physical function score 25 to $<50^{b}$ & 146 & $0.664^{\text {acd }}$ & 0.173 & \\
\hline & Physical function score 50 to $<75^{c}$ & 143 & $0.475^{\mathrm{abd}}$ & 0.205 & \\
\hline & Physical function score 75 to $100^{d}$ & 63 & $0.230^{\mathrm{abc}}$ & 0.293 & \\
\hline & WOMAC Score 0 to $<25^{\mathrm{a}}$ & 44 & $0.829^{\mathrm{bcd}}$ & 0.117 & $<0.0001$ \\
\hline & WOMAC Score 25 to $<50^{b}$ & 145 & $0.665^{\text {acd }}$ & 0.172 & \\
\hline & WOMAC Score 50 to $<75^{c}$ & 143 & $0.464^{\mathrm{abd}}$ & 0.220 & \\
\hline & WOMAC Score 75 to $100^{d}$ & 50 & $0.189^{a b c}$ & 0.277 & \\
\hline \multirow[t]{4}{*}{ Oxford Knee Score (OKS) } & Severe $(0-19)^{a}$ & 168 & $0.346^{\mathrm{bcd}}$ & 0.255 & $<0.0001$ \\
\hline & Moderate to severe $(20-29)^{b}$ & 128 & $0.609^{\text {acd }}$ & 0.157 & \\
\hline & Mild to moderate $(30-39)^{c}$ & 74 & $0.780^{\mathrm{abd}}$ & 0.109 & \\
\hline & Satisfactory joint function (40-48) & 21 & $0.879^{\mathrm{abc}}$ & 0.097 & \\
\hline \multirow[t]{8}{*}{ Non-surgery treatments } & No pharmacologic treatment & 53 & 0.579 & 0.299 & 0.321 \\
\hline & Any pharmacologic treatment & 340 & 0.539 & 0.267 & \\
\hline & Symptomatic slow acting drugs for osteoarthritis (SYSADOA) & 50 & 0.564 & 0.247 & $0.567^{*}$ \\
\hline & Non-opioid pain medication & 242 & 0.546 & 0.263 & $0.919^{*}$ \\
\hline & Nonsteroidal anti-inflammatory drugs (NSAID) & 152 & 0.529 & 0.283 & $0.529^{*}$ \\
\hline & Opiate derivatives & 96 & 0.538 & 0.274 & $0.836^{*}$ \\
\hline & Opioid pain medication & 21 & 0.333 & 0.309 & $0.005^{*}$ \\
\hline & Rehabilitation / Physiotherapy & 14 & 0.559 & 0.295 & $0.854^{*}$ \\
\hline \multirow[t]{3}{*}{ Knee replacement } & Waiting for prosthesis & 92 & 0.400 & 0.266 & $<0.0001^{* *}$ \\
\hline & Prosthesis in the last 6 months & 65 & 0.683 & 0.243 & \\
\hline & Complication after prosthesis & 2 & 0.424 & 0.007 & - \\
\hline
\end{tabular}

BMI Body mass index, SD Standard deviation, WOMAC Western Ontario and McMaster Universities Osteoarthritis Index

$p$-values represents the significance of differences between groups by means of ANOVA except for $(*) P$-value comparing with the whole sample's utility value (0.544) (one sample $t$-test), and $\left({ }^{*}\right) P$-value comparing sample before and after (6 months) the prosthesis (paired sample $t$-test)

Superscript letters indicate differences among the subgroups according to Tamhane's T2 post hoc test for multiple comparisons at $P$-value $<0.01$

care health centers, the remainder were recruited in hospital. A total of $28 \%$ have osteoarthritis in both hips. Average scores of self-administered questionnaires, WOMAC, OHS and EQ-5D-5 L Index, were respectively, 50.69 (SD: 22.25), 22.84 (SD: 22.25), and 0.520 (SD: 0.304).

The most common health state (11111) corresponds to a patient with perfect health. The second most common health state (33331) corresponds to a patient with moderate problems in all dimensions except anxiety/depression where there are no problems (Additional file 1: Table S3). By dimensions, the most common moderate level was for mobility (39.3\%), self-care (31.3\%), usual activities (37.1\%) and pain/discomfort (34.9\%). For anxiety/ depression $43.2 \%$ of the sample reported not having any problems. Levels 4 and 5 (severe and extreme) were reported less commonly although $30.2 \%$ of patients reported having severe pain or discomfort and $23.3 \%$ reported severe problems in mobility (Table 4). Among the 26 patients that reported negative utility values, the most common health state was 44444 (6 patients).

Table 5 shows the health state utilities for different population subgroups. No statistically significant differences were detected between groups according to age, sex, BMI, joint with osteoarthritis (right or left), time since diagnosis (years), with or without prosthesis in the other joint. Differences identified depending on region of residence and number of comorbidities $(P<0.0001$; ANOVA) disappeared when multiple comparison tests were conducted. Regarding clinical questionnaires (level of pain, stiffness and physical function according to WOMAC, and OHS), differences were found between all subgroups $(P<0.0001)$, that is, the less joint problems, the higher utilities. For example, utilities varied according to the degree of severity using the OHS from of 0.269 (severe) to 0.903 (satisfactory function). There was no difference between receiving and not receiving any pharmacologic treatment $(P=0.321)$. During the 6-month follow up, 65 out of 97 people waiting for a prosthesis had the THR. There was an increase in the utility index after the THR $(P<0.0001)$.

Results of the literature review and comparison with the primary study in Spanish population

Using the bibliographical search 116 references were identified of which 79 did not fulfill the inclusion 
Table 4 Percentage of patients with hip osteoarthritis reporting levels within EQ-5D-5 L dimensions

\begin{tabular}{|c|c|c|c|c|c|c|}
\hline Group & Dimension & Level 1 & Level 2 & Level 3 & Level 4 & Level 5 \\
\hline \multirow{5}{*}{$\begin{array}{l}\text { The whole sample } \\
(N=361)\end{array}$} & Mobility & 10.5 & 23.8 & 39.3 & 23.3 & 2.8 \\
\hline & Self-care & 25.2 & 27.7 & 31.3 & 13.6 & 1.9 \\
\hline & Usual activities & 16.6 & 23.0 & 37.1 & 17.2 & 5.8 \\
\hline & Pain/Discomfort & 8.3 & 20.2 & 34.9 & 30.2 & 6.1 \\
\hline & Anxiety/Depression & 43.2 & 23.2 & 18.0 & 10.8 & 3.9 \\
\hline \multirow{5}{*}{$\begin{array}{l}\text { OHS - severe } \\
(N=149)\end{array}$} & Mobility & 0.7 & 3.4 & 38.9 & 50.3 & 6.7 \\
\hline & Self-care & 4.0 & 12.8 & 49.0 & 30.2 & 4.0 \\
\hline & Usual activities & 2.0 & 5.4 & 43.6 & 36.9 & 12.1 \\
\hline & Pain/Discomfort & 0 & 4.0 & 24.2 & 58.4 & 13.4 \\
\hline & Anxiety/Depression & 21.5 & 19.5 & 31.5 & 18.8 & 8.7 \\
\hline \multirow{5}{*}{$\begin{array}{l}\text { OHS - moderate to severe } \\
(N=116)\end{array}$} & Mobility & 3.4 & 32.8 & 56.9 & 6.9 & 0 \\
\hline & Self-care & 20.7 & 44.0 & 32.8 & 2.6 & 0 \\
\hline & Usual activities & 8.6 & 36.2 & 47.4 & 6.0 & 1.7 \\
\hline & Pain/Discomfort & 1.7 & 21.6 & 57.8 & 18.1 & 0.9 \\
\hline & Anxiety/Depression & 43.1 & 35.3 & 11.2 & 9.5 & 0.9 \\
\hline \multirow{5}{*}{$\begin{array}{l}\text { OHS - mild to moderate } \\
(N=61)\end{array}$} & Mobility & 26.2 & 50.8 & 23.0 & 0 & 0 \\
\hline & Self-care & 55.7 & 39.3 & 3.3 & 1.6 & 0 \\
\hline & Usual activities & 39.3 & 42.6 & 18.0 & 0 & 0 \\
\hline & Pain/Discomfort & 16.4 & 52.5 & 29.5 & 1.6 & 0 \\
\hline & Anxiety/Depression & 73.8 & 18.0 & 8.2 & 0 & 0 \\
\hline \multirow{5}{*}{$\begin{array}{l}\text { OHS - satisfactory joint function } \\
(N=29)\end{array}$} & Mobility & 58.6 & 27.6 & 13.8 & 0 & 0 \\
\hline & Self-care & 86.2 & 13.8 & 0 & 0 & 0 \\
\hline & Usual activities & 72.4 & 20.7 & 6.9 & 0 & 0 \\
\hline & Pain/Discomfort & 58.6 & 31.0 & 10.3 & 0 & 0 \\
\hline & Anxiety/Depression & 93.1 & 6.9 & 0 & 0 & 0 \\
\hline
\end{tabular}

Level 1: indicating no problem; Level 2: indicating slight problems; Level 3: indicating moderate problems; Level 4: indicating severe problems; Level 5: indicating extreme problems

Highest frequencies are highlighted in bold letters

criteria (Additional file 1: Figure S1). Of the 37 economic evaluations that did fulfill the inclusion criteria, 16 were not included in the CEA Registry or they were included but did not report utilities but rather QALYs and 6 included health states for which our database could not obtain utilities. Consequently, 15 papers were selected to extract health states and utilities, 10 in subjects with KOA [41-50], 4 in subjects with $\mathrm{HOA}$ [51-54], 1 in both [55]. These economic evaluations were performed in the USA (9), Canada (3), Germany (1), the United Kingdom (1), and Taiwan (1). Of these 15 papers, the CEA Registry included a total of 149 health states with their corresponding utilities. Using our Spanish database, it is not possible to estimate utilities for 61 out of the 149 health states. The main reason was that the health states were directly related to the consequences of joint replacement (complications, long-term outcomes) or with other technologies. Of the 88 states, a significant number of repeated health states-utilities pairs were identified because they were reported by the same authors using the same source $[44,45]$. Therefore, a total of 51 pairs of health statesutilities (health states and their associated utilities) were selected: 45 pairs of health states-utilities for knee (Additional file 1: Table S4) and six pairs of health states-utilities for the hip (Additional file 1: Table S5). Several of these health states could be considered equivalent given their definition although there is heterogeneity in the definitions and/or values of utilities found in the literature. For example, three authors used in their models in KOA patients three apparently similar states of health but with clearly different utilities values: Osteoarthritis with conventional treatment (utility $=0.85$ ) [50]; End stage knee osteoarthritis with treatment bridge (utility $=0.7$ ) [46]; Conservative treatment (baseline) for knee osteoarthritis (utility $=0.55$ ) [42]. Differences in these values may be for different reasons such as population characteristics or method 
Table 5 Utility weights (EQ-5D-5 L Index) per subgroup in patients with hip osteoarthritis

\begin{tabular}{|c|c|c|c|c|c|}
\hline Subgroup & & $\mathrm{N}$ & Mean & SD & $P$-value \\
\hline \multirow[t]{6}{*}{ Age groups (years) } & $<45$ & 13 & 0.591 & 0.357 & 0.259 \\
\hline & $45-54.99$ & 37 & 0.506 & 0.291 & \\
\hline & $55-64.99$ & 83 & 0.465 & 0.291 & \\
\hline & $65-74.99$ & 101 & 0.507 & 0.298 & \\
\hline & $75-84.99$ & 103 & 0.562 & 0.299 & \\
\hline & $\geq 85$ & 20 & 0.584 & 0.380 & \\
\hline \multirow[t]{2}{*}{ Gender } & Women & 188 & 0.512 & 0.305 & 0.606 \\
\hline & Men & 169 & 0.529 & 0.304 & \\
\hline \multirow[t]{3}{*}{ Region } & Basque Country ${ }^{a}$ & 154 & 0.473 & 0.313 & 0.036 \\
\hline & Madrid $^{\mathrm{b}}$ & 124 & 0.553 & 0.288 & \\
\hline & Canary Islands ${ }^{c}$ & 79 & 0.562 & 0.301 & \\
\hline \multirow[t]{5}{*}{ BMI categories } & Underweight & 2 & 0.339 & 0.572 & 0.372 \\
\hline & Normal & 87 & 0.552 & 0.305 & \\
\hline & Overweight & 154 & 0.530 & 0.288 & \\
\hline & Obesity & 102 & 0.473 & 0.324 & \\
\hline & Morbid obesity & 5 & 0.541 & 0.241 & \\
\hline \multirow[t]{3}{*}{ Joint with osteoarthritis } & Right hip & 135 & 0.481 & 0.320 & 0.059 \\
\hline & Left hip & 121 & 0.571 & 0.285 & \\
\hline & Both hip & 101 & 0.511 & 0.297 & \\
\hline \multirow[t]{5}{*}{ Time since osteoarthritis diagnosis (years) } & $<1$ & 118 & 0.541 & 0.279 & 0.240 \\
\hline & 1 to $<5$ & 152 & 0.492 & 0.309 & \\
\hline & 5 to $<10$ & 63 & 0.520 & 0.347 & \\
\hline & 10 to $<15$ & 14 & 0.675 & 0.204 & \\
\hline & $\geq 15$ & 8 & 0.523 & 0.288 & \\
\hline \multirow[t]{2}{*}{ Contralateral hip } & Without prosthesis in the other hip & 293 & 0.510 & 0.303 & 0.182 \\
\hline & With prosthesis in the other hip & 62 & 0.567 & 0.302 & \\
\hline \multirow[t]{4}{*}{ Other joints } & Knee osteoarthritis & 115 & 0.522 & 0.322 & 0.303 \\
\hline & No knee osteoarthritis & 241 & 0.521 & 0.295 & \\
\hline & Osteoarthritis in other joints & 214 & 0.537 & 0.301 & 0.801 \\
\hline & No osteoarthritis in other joints & 142 & 0.499 & 0.306 & \\
\hline \multirow[t]{5}{*}{ Number of comorbidities (Charlson Index) } & No comorbidity ${ }^{a}$ & 206 & 0.561 & 0.284 & 0.033 \\
\hline & 1 comorbidity $^{\mathrm{b}}$ & 71 & 0.465 & 0.323 & \\
\hline & 2 comorbidities $^{c}$ & 46 & 0.495 & 0.334 & \\
\hline & 3 comorbidities $^{d}$ & 18 & 0.386 & 0.370 & \\
\hline & $\geq 4$ comorbidities $^{\mathrm{e}}$ & 16 & 0.460 & 0.210 & \\
\hline \multirow[t]{9}{*}{ WOMAC } & Pain score 0 to $<25^{\mathrm{a}}$ & 54 & $0.818^{\mathrm{bcd}}$ & 0.146 & $<0.0001$ \\
\hline & Pain score 25 to $<50^{b}$ & 143 & $0.643^{\text {acd }}$ & 0.175 & \\
\hline & Pain score 50 to $<75^{c}$ & 110 & $0.414^{\mathrm{abd}}$ & 0.243 & \\
\hline & Pain score 75 to $100^{d}$ & 49 & $0.074^{\mathrm{abc}}$ & 0.250 & \\
\hline & Stiffness score 0 to $<25^{a}$ & 42 & $0.795^{\mathrm{bcd}}$ & 0.181 & $<0.0001$ \\
\hline & Stiffness score 25 to $<50^{\mathrm{b}}$ & 107 & $0.656^{\text {acd }}$ & 0.220 & \\
\hline & Stiffness score 50 to $<75^{c}$ & 118 & $0.509^{\mathrm{abd}}$ & 0.241 & \\
\hline & Stiffness score 75 to $100^{d}$ & 89 & $0.243^{\mathrm{abc}}$ & 0.294 & \\
\hline & Physical function score 0 to $<25^{a}$ & 48 & $0.878^{\mathrm{bcd}}$ & 0.098 & $<0.0001$ \\
\hline
\end{tabular}


Table 5 Utility weights (EQ-5D-5 L Index) per subgroup in patients with hip osteoarthritis (Continued)

\begin{tabular}{|c|c|c|c|c|c|}
\hline Subgroup & & $\mathrm{N}$ & Mean & SD & $P$-value \\
\hline & Physical function score 25 to $<50^{b}$ & 115 & $0.672^{\text {acd }}$ & 0.144 & \\
\hline & Physical function score 50 to $<75^{c}$ & 125 & $0.464^{\mathrm{abd}}$ & 0.225 & \\
\hline & Physical function score 75 to $100^{d}$ & 69 & $0.120^{\mathrm{abc}}$ & 0.229 & \\
\hline & WOMAC Score 0 to $<25^{\mathrm{a}}$ & 47 & $0.864^{\mathrm{bcd}}$ & 0.122 & $<0.0001$ \\
\hline & WOMAC Score 25 to $<50^{b}$ & 124 & $0.673^{\mathrm{acd}}$ & 0.145 & \\
\hline & WOMAC Score 50 to $<75^{c}$ & 120 & $0.429^{\mathrm{abd}}$ & 0.232 & \\
\hline & WOMAC Score 75 to $100^{d}$ & 56 & $0.081^{a b c}$ & 0.222 & \\
\hline \multirow[t]{4}{*}{ Oxford Hip Score (OHS) } & Severe $(0-19)^{a}$ & 149 & $0.269^{\mathrm{bcd}}$ & 0.264 & $<0.0001$ \\
\hline & Moderate to severe $(20-29)^{b}$ & 116 & $0.611^{\text {acd }}$ & 0.146 & \\
\hline & Mild to moderate $(30-39)^{c}$ & 61 & $0.783^{\mathrm{abd}}$ & 0.101 & \\
\hline & Satisfactory joint function (40-48) & 29 & $0.903^{\mathrm{abc}}$ & 0.102 & \\
\hline \multirow[t]{8}{*}{ Non-surgery treatments } & No pharmacologic treatment & 69 & 0.544 & 0.312 & 0.491 \\
\hline & Any pharmacologic treatment & 287 & 0.516 & 0.301 & \\
\hline & Symptomatic slow acting drugs for osteoarthritis (SYSADOA) & 34 & 0.574 & 0.320 & $0.331^{*}$ \\
\hline & Non-opioid pain medication & 197 & 0.503 & 0.309 & $0.435^{*}$ \\
\hline & Nonsteroidal anti-inflammatory drugs (NSAID) & 128 & 0.533 & 0.304 & $0.613^{*}$ \\
\hline & Opiate derivatives & 97 & 0.498 & 0.304 & $0.474^{*}$ \\
\hline & Opioid pain medication & 13 & 0.435 & 0.378 & $0.434^{*}$ \\
\hline & Rehabilitation / Physiotherapy & 10 & 0.598 & 0.227 & $0.305^{*}$ \\
\hline \multirow[t]{3}{*}{ Hip replacement } & Waiting for prosthesis & 97 & 0.379 & 0.313 & $<0.0001^{* *}$ \\
\hline & Prosthesis in the last 6 months & 65 & 0.730 & 0.208 & \\
\hline & Complication after prosthesis & 5 & 0.556 & 0.432 & - \\
\hline
\end{tabular}

BMI Body mass index; SD Standard deviation; WOMAC Western Ontario and McMaster Universities Osteoarthritis Index

$P$-values represents the significance of differences between groups by means of ANOVA except for $(*) P$-value comparing with the whole sample's utility value (0.520) (one sample $t$-test), and $\left(^{* *}\right) P$-value comparing sample before and after ( 6 months) the prosthesis (paired sample $t$-test)

Superscript letters indicate differences among the subgroups according to Bonferroni (region and number of comorbidities) or Tamhane's T2 (WOMAC, OHS) post hoc tests for multiple comparisons at $P$-value $<0.01$

used to estimate the utilities. In this specific case the first author used standard gamble, the second various bibliographic sources and the third author converted the EQ-5D VAS general population scores into standard gamble utilities. None of the studies explicitly used the EQ-5D index to estimate utilities.

Using our database, we can create and estimate utilities for 39 states approximately equivalent to those identified in the literature, 36 for knee (Additional file 1: Table S4) and 3 for hip (Additional file 1: Table S5). For 9 states it was not possible to estimate any utility because of lack of sample. A qualitative comparison between the values obtained by both sources shows that, in most cases (80\%), the values obtained with our sample are lower than those identified in the literature. Among KOA patients, the largest difference between utilities obtained in the literature and utilities obtained in our sample occurred in health states for which a small sample size was obtained in our observational study. For those states with sample size of at least 30 subjects the largest difference $(0.45$ points) occurred in the state " $0-1$ comorbidity, age $65+$, obese with osteoarthritis related pain'; the lower difference (0.005) and only one lower than 0.045 [40] occurred in the state 'TKR during the last 6 months (WOMAC $<60$ )'. Among patients with $\mathrm{HOA}$, the largest difference $(0.269$ points) occurred in 'severe HOA patients waiting for THR $(0<\mathrm{OHS}<19)$ ' [51] and the lowest difference (0.07) occurred in 'THR during the last 6 months' and only when we compare with one of the studies found in the literature [52].

\section{Discussion}

This study aimed to obtain utilities by means of the EQ5D-5 L questionnaire for different health states in KOA or HOA patients using an observational study performed in Spain and subsequently comparing these values with others obtained in international studies. Firstly, from our observational Spanish study, the average utility of samples with KOA and HOA were 0.544 and 0.520 , respectively. The analysis of samples by subgroups revealed statistically significant differences according to level of pain, stiffness and physical function according to WOMAC and Oxford scales such that the worse the 
health condition the worse the utility. The validity of the instruments WOMAC [37] and OKH and OKS [30, 31] in Spain and their use in clinical practice support the use of these instruments to determine health states in economic evaluations. Consequently, the health state utility values obtained should be in mind for future economic studies.

To our knowledge, this is the first article whose aim was the characterization of utilities by health states in $\mathrm{KOA}$ and HOA from Spanish population by means of the most recent version of the EQ-5D questionnaire, the EQ-5D-5 L [11]. Previously the EQ-5D-5 L was used in the National Health Survey of Spain 2011/2012 [56]. In this survey it was observed that utility is worse as age increases and lower for women than men just as in our study. However, the values of utilities are far higher than ours because populations are very different. The National Survey questioned non-institutionalized persons (interviewed at home) who stated they had a diagnosis of arthrosis without specifying the joint involved.

Conversely, a review of utilities obtained from the Spanish population identified 6 prior studies focused mainly on joint replacement and in which the EQ-5D-5 $\mathrm{L}$ questionnaire was not used [11]. Three of them used the EQ-5D-3L [15-17]. One consisted of a prospective study in which the utility was evaluated before surgery (0.2 for knee and 0.47 for hip) and at 6 months (0.64 and 0.55 respectively, $n=40$ for each estimate) [15]. In our study as expected there was a difference in the utility index before and after the prosthesis in both knee and hip, although values are substantially different to those obtained in our database probably because of the characteristics of the sample and differences in estimation between the 3 and 5 level version of the EQ-5D [57]. The psychometric qualities of the 5-level questionnaire defend its use in detriment to the 3-level questionnaire as the former is a more precise measure than the latter $[57,58]$. Therefore, the average values of utilities obtained using our sample with the EQ-5D-5L are more precise for characterization of health states in a future CUA study in comparison with values available up to now, apart from facilitating the necessary information (dispersion measures) to analyze the robustness of the model by means of a probabilistic sensitivity analysis.

Secondly, a literature review was carried out that aimed to compare international utilities with our utilities for similar health states. The first impression obtained from the literature review is the low number of publications in HOA patients in comparison to the literature available for KOA patients. The second impression is that, in general, utilities obtained in our observational study are lower than those collated in the literature. However, statistical comparisons between both were not conducted given that none of the studies identified in the review used the EQ-5D index, so a qualitative comparison was conducted and minimally relevant value according to McClure et al. was used [40]. It was possible to obtain and compare health states and utilities from our Spanish observational study for a significant number of health states and utilities used in international economic evaluations. Using Spanish utilities it could be possible to replicate all the models identified in the literature review except for two of them $[45,49]$. One of them defined very specific conditions for which we do not have utilities for all of them [45]. Another evaluated among others the condition "Treatment of infection", for which we only have one patient in our sample [49]. The qualitative analysis of the health states enables us to see the variety of forms in which an apparently same health state or condition can be defined [7]. These definitions, apart from the different methods to elicit the utilities and population/context differences [7], can be accounted for by differences in values found in literature and values estimated by ourselves. In any case, higher differences than the minimally relevant value according to McClure [40] were identified in almost $100 \%$ of cases. This shows the importance of appropriately choosing values of parameters in the models to avoid the economic evaluation being artificially affected [7].

Limitations of this study include those arising from the study design. First, a sample with broad criteria to recruit subjects with osteoarthritis leads, as expected, to a heterogeneous sample which necessarily is insufficient (in size) when we wish to characterize multiple population subgroups [59]. Consequently, the sample was heterogeneous in terms of treatments received and there was a small sample size to associate utilities with specific technologies such as prosthesis or medicines after surgery [59]. Second, the criteria used to define health states including cut-off points are at times arbitrary and other criteria may be necessary to define conditions in a future economic model [7]. Third, none of the studies included in the review used the EQ-5D-5 L questionnaire which is the one used in our observational study, whereby the differences observed should be taken with caution as they arise in part from different methods and instruments [7]. Four, the literature review was tackled pragmatically and with illustrative purposes, whereby it is under no circumstances an exhaustive review.

Finally, interesting analysis could not be performed. From a theoretic point of view, it would be desirable for economic evaluations performed in Spain to use values of utilities obtained by means of appropriate methods on a Spanish population. However, this is not always possible, and we must resort to review of literature reporting foreign population values [7]. This is the case of all the Spanish economic evaluations we have identified [24-26]. All of them used utilities from foreign studies 
in which EQ-5D was not used rather than other methods/instruments such as standard gamble or 15D questionnaire. These three studies evaluated the costeffectiveness of prophylaxis medicines for the prevention of venous thromboembolism after TKR or THR [24-26]. Some health states in the studies were symptomatic deep-vein thrombosis or pulmonary embolism [24-26]. Because our study is observational and has a heterogeneous sample with short sample sizes for some subgroups [59], utilities could not be obtained for all these conditions related to post-surgery, whereby it was not possible to analyze the effect that using Spanish utilities would have meant.

The selection of utility values from foreign studies to be used in an economic evaluation model should be performed carefully taking care to ensure that the value chosen for the health condition is as real as possible but also making sure that the values used for all conditions considered in the economic model are coherent $[7,28,59]$. The main threat to this coherence is using data from different sources [7]. Therefore, observational or experimental studies that help to ascertain and characterize local populations are necessary [59]. Ideally, it should be possible to incorporate patient-report outcome measurements such as the EQ-5D$5 \mathrm{~L}$ into electronic clinical records [60] with the purpose of being able to routinely collate and use data that will be very useful for the economic evaluation of healthcare technologies [59]. Most authors have been interested in the costutility of total joint replacement [61] but these are not the only treatments, especially in early stages of osteoarthritis $[20,21]$. Utility data estimated in our study may be of interest for researchers seeking to evaluate the cost-utility of these other alternatives in Spain.

\section{Conclusions}

To sum up, the following conclusions can be drawn from the primary study and literature review. First, the worse the health condition in terms of level of pain, stiffness and physical function according to WOMAC and Oxford scales, the lower the utilities obtained by means of the EQ-5D-5 L questionnaire in Spain for both KOA and HOA. Secondly, this observational study offers values of utilities that to date were not available for a significant variety of health states. Thirdly, most utilities estimated with the Spanish sample are lower than those collated in the international studies identified. Finally, despite an observational study such as this having a broad sample this may not be sufficient to offer utilities for all possible health states related to existing technologies, it enables obtaining utilities directly from the local population which is necessary to help characterize and find out about these populations such that values of utilities used in future CUA performed in Spain are as close as possible to the country's cultural reality.

\section{Supplementary information}

Supplementary information accompanies this paper at https://doi.org/10. 1186/s12955-019-1230-x.

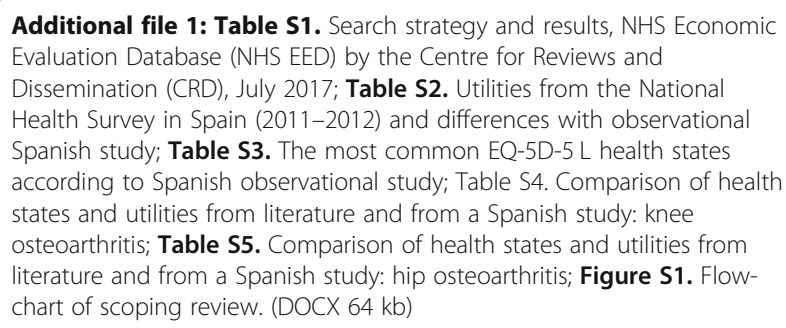

\section{Abbreviations}

BMI: Body Mass Index; CUA: Cost-utility analysis; HOA: Hip osteoarthritis; HRQoL: Health-Related Quality of Life; KOA: Knee osteoarthritis;

NSAID: Nonsteroidal anti-inflammatory drugs; OHS: Oxford Hip Score; OKS: Oxford Knee Score; QALY: Quality-adjusted life years; SD: Standard deviation; SYSADOA: Symptomatic slow acting drugs for osteoarthritis; THR: Total hip replacement; TKR: Total knee replacement; WOMAC: Western Ontario and McMaster Universities Osteoarthritis Index

\section{Acknowledgements}

We are grateful to colleagues in the participating hospitals and primary care centers for their support and to all patients for their collaboration. The authors would also like to thank Jason Willis-Lee for translation and copyediting support and Yolanda Ramallo for her advice.

\section{Authors' contributions}

LGP, PSA, JMF, and AB designed the study. LGP, VRG, JLPB, MAM, JMF, RCGM, $J C A$, and $A B$ executed the study. $L G P, V R G, J M F$, and $A B$ analyzed the data. $L G P, V R G, J M F$, and $A B$ wrote the paper. All authors revised and approved the final manuscript.

\section{Funding}

This study has been financed by Instituto de Salud Carlos III and FEDER (European Regional Development Fund) (PI1300560, PI1300518, PI1300648).

\section{Availability of data and materials}

The datasets used or analyzed during the current study are available from the corresponding author upon reasonable request.

\section{Ethics approval and consent to participate}

All patients gave written consent for participation.

This study received the approval of the following Ethics Committees for Clinical Research: ECCR of Euskadi (PI2014050), Hospital Fundación Jiménez Díaz (PIC 80/2013_HRJC), Hospital Universitario de Fuenlabrada (APR 14-27), Hospital Universitario Fundación Alcorcón (14/19), Hospital Universitario de Canarias (2014-109), Hospital Universitario Nuestra Señora de Candelaria (PI-09/15)

\section{Consent for publication}

Not applicable.

\section{Competing interests}

The authors declare that they have no competing interests.

\section{Author details}

${ }^{1}$ Fundación Canaria de Investigación Sanitaria (FUNCANIS), Camino Candelaria No 44, 1a planta. 38109 El Rosario, Santa Cruz de Tenerife, Spain. ${ }^{2}$ Servicio de Evaluación del Servicio Canario de la Salud (SESCS), Camino Candelaria No 44, 1a planta. 38109 El Rosario, Santa Cruz de Tenerife, Spain ${ }^{3}$ Health Services Research on Chronic Patients Network (REDISSEC), Bilbao, Spain. ${ }^{4}$ Instituto Universitario de Desarrollo Regional (IUDR), University of La Laguna, San Cristóbal de La Laguna, Spain. ${ }^{5}$ Centro de Investigaciones Biomédicas de Canarias (CIBICAN), San Cristóbal de La Laguna, Spain. ${ }^{6}$ Department of Orthopaedics and Traumatology, University Hospital of Canary Islands, Ctra. Ofra S/N La Cuesta, 38320 La Laguna, Tenerife, Spain. 
${ }^{7}$ Department of Orthopaedics and Traumatology, University of La Laguna, San Cristóbal de La Laguna, Spain. ${ }^{8}$ Multiprofessional Teaching Unit of Primary and Community Care "Oeste", Health Service, c/ Alonso Cano 8, Móstoles, 28933 Madrid, Madrid, Spain. ${ }^{9}$ Health Sciences Faculty, Rey Juan Carlos University, Madrid, Spain. ${ }^{10}$ Traumatology and Orthopedic Surgery Service, Hospital Universitario Clínico San Carlos, C/ Profesor Martín Lagos S/ N, 28040 Madrid, Spain. ${ }^{11}$ Traumatology and Orthopedic Surgery Service, Basurto University Hospital (Osakidetza), Avda. Montevideo, 18, 48013 Bilbao, Bizkaia, Spain. ${ }^{12}$ Research Unit, Basurto University Hospital (Osakidetza), Avda. Montevideo, 18, 48013 Bilbao, Bizkaia, Spain.

\section{Received: 19 March 2019 Accepted: 3 October 2019}

Published online: 30 October 2019

\section{References}

1. Pereira D, Peleteiro B, Araújo J, Branco J, Santos RA, Ramos E. The effect of osteoarthritis definition on prevalence and incidence estimates: a systematic review. Osteoarthr Cartil. 2011;19:1270-85.

2. Xie F, Kovic B, Jin X, He X, Wang M, Silvestre C. Economic and humanistic burden of osteoarthritis: a systematic review of large sample studies. Pharmacoeconomics. 2016;34:1087-100

3. van der Waal JM, Terwee CB, van der Windt DAWM, Bouter LM, Dekker J. The impact of non-traumatic hip and knee disorders on health-related quality of life as measured with the SF-36 or SF-12. A systematic review. Qual Life Res. 2005;14:1141-55.

4. Puig-Junoy J, Ruiz ZA. Socio-economic costs of osteoarthritis: a systematic review of cost-of-illness studies. Semin Arthritis Rheum. 2015;44:531-41.

5. Loza E, Lopez-Gomez JM, Abasolo L, Maese J, Carmona L, Batlle-Gualda E, et al. Economic burden of knee and hip osteoarthritis in Spain. Arthritis Rheum. 2009:61:158-65.

6. Drummond MF, Sculpher MJ, Torrance GW, O'Brien BJ, Stoddart GL. Methods for the Economic Evaluation of Health Care Programmes. 3rd Edition. New York: Oxford University Press; 2005.

7. Brazier J, Ara R, Azzabi I, Busschbach J, Chevrou-Séverac H, Crawford B, et al. Identification, review, and use of health state utilities in cost-effectiveness models: an ISPOR good practices for outcomes research task force report. Value Health. 2019:22:267-75.

8. Vallejo-Torres L, García-Lorenzo B, Castilla I, Valcárcel-Nazco C, García-Pérez $L$, Linertová $R$, et al. On the estimation of the cost-effectiveness threshold: why, what, how? Value Health. 2016;19:558-66.

9. Vallejo-Torres L, García-Lorenzo B, Serrano-Aguilar P. Estimating a costeffectiveness threshold for the Spanish NHS. Heal Econ. 2018;27:746-61.

10. EuroQol Group. EuroQol--a new facility for the measurement of healthrelated quality of life. Health Policy. 1990;16:199-208.

11. García-Pérez L, Pinilla-Domínguez P, Aguiar-lbáñez R, Linertová R, RiveroSantana A, Abásolo-Alessón I. Revisión sistemática de utilidades o preferencias por los estados de salud obtenidas de población española. Madrid: Ministerio de Sanidad, Servicios Sociales e Igualdad. Servicio de Evaluación del Servicio Canario de la Salud; 2011.

12. Herdman M, Gudex C, Lloyd A, Janssen M, Kind P, Parkin D, et al. Development and preliminary testing of the new five-level version of EQ-5D (EQ-5D-5L). Qual Life Res. 2011:20:1727-36.

13. Ramos-Goñi JM, Craig BM, Oppe M, Ramallo-Fariña Y, Pinto-Prades JL, Luo N, et al. Handling data quality issues to estimate the Spanish EQ-5D-5L value set using a hybrid interval regression approach. Value Health. 2018;21:596-604.

14. Bilbao A, García-Pérez L, Arenaza JC, García I, Ariza-Cardiel G, Trujillo-Martín E, et al. Psychometric properties of the EQ-5D-5L in patients with hip or knee osteoarthritis: reliability, validity and responsiveness. Qual Life Res. 2018:27:2897-908

15. Navarro Espigares $J$, Hernández Torres E. Cost-outcome analysis of joint replacement: evidence from a Spanish public hospital. Gac Sanit. 2008;22:337-43.

16. Gonzalez Sáenz de Tejada M, Escobar A, Herrera C, García L, Aizpuru F, Sarasqueta C. Patient expectations and health-related quality of life outcomes following total joint replacement. Value Health. 2010;13:447-54.

17. Allepuz A, Espallargues M, Moharra M, Comas M, Pons JM V, Research group on support instruments - IRYSS network. Prioritisation of patients on waiting lists for hip and knee arthroplasties and cataract surgery: instruments validation. BMC Health Serv Res. 2008;8:76.

18. Chawla H, Ghomrawi HM, van der List JP, Eggman AA, Zuiderbaan HA, Pearle AD. Establishing age-specific cost-effective annual revision rates for unicompartmental knee arthroplasty: a meta-analysis. J Arthroplasty. 2017 32:326-35.

19. Clarke A, Pulikottil-Jacob R, Grove A, Freeman K, Mistry H, Tsertsvadze A, et al. Total hip replacement and surface replacement for the treatment of pain and disability resulting from end-stage arthritis of the hip (review of technology appraisal guidance 2 and 44): systematic review and economic evaluation. Health Technol Assess. 2015;19:1-668, vii-viii.

20. Brockbank J, Wolowacz S. Economic evaluations of new oral anticoagulants for the prevention of venous thromboembolism after total hip or knee replacement: a systematic review. Pharmacoeconomics. 2017;35:517-35.

21. Pinto D, Robertson MC, Hansen P, Abbott JH. Cost-effectiveness of nonpharmacologic, nonsurgical interventions for hip and/or knee osteoarthritis: Systematic review. Value Health. 2012;15:1-12.

22. Hiligsmann M, Cooper C, Arden N, Boers M, Branco JC, Luisa Brandi M, et al. Health economics in the field of osteoarthritis: an Expert's consensus paper from the European Society for Clinical and Economic Aspects of osteoporosis and osteoarthritis (ESCEO). Semin Arthritis Rheum. 2013;43:303-13.

23. Catalá-López F, Ridao M, Alonso-Arroyo A, García-Altés A, Cameron C, González-Bermejo D, et al. The quality of reporting methods and results of cost-effectiveness analyses in Spain: a methodological systematic review. Syst Rev. 2016;5:6

24. Gómez-Outes A, Avendaño-Solá C, Terleira-Fernández Al, Vargas-Castrillón E. Pharmacoeconomic evaluation of Dabigatran, rivaroxaban and Apixaban versus enoxaparin for the prevention of venous thromboembolism after total hip or knee replacement in Spain. Pharmacoeconomics. 2014;32:919-36.

25. Monreal M, Folkerts K, Diamantopoulos A, Imberti D, Brosa M. Costeffectiveness impact of rivaroxaban versus new and existing prophylaxis for the prevention of venous thromboembolism after total hip or knee replacement surgery in France, Italy and Spain. Thromb Haemost. 2013; 110:987-94

26. Suárez Fernández C, Gómez Cerezo JF, Gómez Arrayás I, Betegón Nicolás L, de Salas-Cansado M, Rubio-Terrés C. Análisis de coste-efectividad de apixaban frente a enoxaparina en la prevención del tromboembolismo venoso en la artroplastia total de rodilla o cadera. PharmacoEconomics Spanish Res Artic. 2013;10:107-18.

27. Drummond M, Barbieri M, Cook J, Glick HA, Lis J, Malik F, et al. Transferability of economic evaluations across jurisdictions: ISPOR good research practices task force report. Value Health. 2009:12:409-18.

28. Heijink R, Reitmeir P, Leidl R. International comparison of experience-based health state values at the population level. Health Qual Life Outcomes. 2017;15:138.

29. Altman RD. Criteria for classification of clinical osteoarthritis. J Rheumatol Suppl. 1991;27:10-2.

30. Martín-Fernández J, García-Maroto R, Sánchez-Jiménez FJ, Bau-González A, Valencia-García H, Gutiérrez-Teira B, et al. Validation of the Spanish version of the Oxford knee score and assessment of its utility to characterize quality of life of patients suffering from knee osteoarthritis: a multicentric study. Health Qual Life Outcomes. 2017;15:186.

31. Martín-Fernández J, Gray-Laymón P, Molina-Siquero A, Martínez-Martín J, García-Maroto R, García-Sánchez I, et al. Cross-cultural adaptation and validation of the Spanish version of the Oxford Hip Score in patients with hip osteoarthritis. BMC Musculoskelet Disord. 2017;18:205.

32. Charlson ME, Pompei $P$, Ales $K L$, Mackenzie CR. A new method of classifying prognostic comorbidity in longitudinal studies: development and validation. J Chronic Dis. 1987:40:373-83.

33. Dawson J, Fitzpatrick R, Murray D, Carr A. Questionnaire on the perceptions of patients about total knee replacement. J Bone Joint Surg Br. 1998;80:63-9.

34. Dawson J, Fitzpatrick R, Carr A, Murray D. Questionnaire on the perceptions of patients about total hip replacement. J Bone Joint Surg Br. 1996:78:185-90.

35. Bellamy N, Buchanan WW, Goldsmith CH, Campbell J, Stitt LW. Validation study of WOMAC: a health status instrument for measuring clinically important patient relevant outcomes to antirheumatic drug therapy in patients with osteoarthritis of the hip or knee. J Rheumatol. 1988;15:1833-40.

36. Orthopaedic Score [Internet]. Available from: http://www.orthopaedicscore.com [2017 July 9].

37. Escobar A, Quintana JM, Bilbao A, Azkárate J, Güenaga JI. Validation of the Spanish version of the WOMAC questionnaire for patients with hip or knee osteoarthritis. Western Ontario and McMaster universities osteoarthritis index. Clin Rheumatol. 2002;21:466-71.

38. Ministerio de Sanidad Servicios Sociales e Igualdad. Encuesta Nacional de Salud de España 2011/12 [Internet]. [cited 2019 Sep 3]. Available from: 
https://www.mscbs.gob.es/estadEstudios/estadisticas/encuestaNacional/ encuesta2011.htm

39. Center for the Evaluation of Value and Risk in Health. The Cost-Effectiveness Analysis Registry [Internet]. (Boston), Institute for Clinical Research and Health Policy Studies, Tufts Medical Center. Available from: www.cearegistry.org. Accessed 8 Aug 2019.

40. McClure NS, Sayah FA, Xie F, Luo N, Johnson JA. Instrument-Defined Estimates of the Minimally Important Difference for EQ-5D-5L Index Scores. Value Health. 2017;20:644-50.

41. Li CS, Bhandari M. Cost-effectiveness of unicompartmental knee arthroplasty, high tibial osteotomy, and KineSpring ${ }^{\circledR}$ Knee Implant System for unicompartmental osteoarthritis of the knee. J Long Term Eff Med Implants. 2013;23:189-98.

42. Li CS, Seeger T, Auhuber TC, Bhandari M. Cost-effectiveness and economic impact of the KineSpring ${ }^{\oplus}$ knee implant system in the treatment for knee osteoarthritis. Knee Surg Sport Traumatol Arthrosc. 2013;21:2629-37.

43. Losina E, Walensky RP, Kessler CL, et al. Cost-effectiveness of total knee arthroplasty in the United States: patients risk and hospital volume. Arch Intern Med. 2009;169:1113-22.

44. Losina E, Burbine SA, Suter LG, Hunter DJ, Solomon DH, Daigle ME, et al. Pharmacologic regimens for knee osteoarthritis prevention: can they be cost-effective? Osteoarthr Cartil. 2014;22:415-30.

45. Losina E, Daigle ME, Suter LG, Hunter DJ, Solomon DH, Walensky RP, et al. Disease-modifying drugs for knee osteoarthritis: can they be cost-effective? Osteoarthr Cartil. 2013;21:655-67.

46. Mather RC, Hug KT, Orlando LA, Watters TS, Koenig L, Nunley RM, et al. Economic evaluation of access to musculoskeletal care: the case of waiting for total knee arthroplasty. BMC Musculoskelet Disord. 2014;15:22.

47. Nelson RE, Battistone MJ, Ashworth WD, Barker AM, Grotzke M, Huhtala TA, et al. Cost effectiveness of training rural providers to perform joint injections. Arthritis Care Res. 2014;66:559-66.

48. Novak EJ, Silverstein MD, Bozic KJ. The cost-effectiveness of computerassisted navigation in total knee arthroplasty. J Bone Jt Surg - Ser A. 2007; 89:2389-97.

49. Soohoo NF, Sharifi H, Kominski G, Liebeuman JR. Cost-effectiveness analysis of unicompartmental knee arthroplasty as an alternative to total knee arthroplasty for unicompartmental osteoarthritis. J Bone Jt Surg - Ser A. 2006;88:1975-82

50. Yen Z-S, Lai M-S, Wang C-T, Chen L-S, Chen S-C, Chen W-J, et al. Costeffectiveness of treatment strategies for osteoarthritis of the knee in Taiwan. J Rheumatol. 2004;31:1797-803.

51. Bozic K, Pui CM, Ludeman MJ, Vail TP, Silverstein MD. Do the potential benefits of metal-on-metal hip resurfacing justify the increased cost and risk of complications? Clin Orthop Relat Res. 2010;468:2301-12.

52. Cummins JS, Tomek IM, Kantor SR, Furnes O, Engesæter LB, Finlayson SRG. Cost-effectiveness of antibiotic-impregnated bone cement used in primary total hip arthroplasty. J Bone Jt Surg - Ser A. 2009;91:634-41.

53. Heintzbergen S, Kulin NA, ljzerman MJ, Steuten LMG, Werle J, Khong H, et al. Cost-utility of metal-on-metal hip resurfacing compared to conventional total hip replacement in young active patients with osteoarthritis. Value Health. 2013;16:942-52.

54. McKenzie L, Vale L, Stearns S, McCormack K. Metal on metal hip resurfacing arthroplasty: an economic analysis. Eur J Health Econ. 2003;4:122-9.

55. Tso P, Walker K, Mahomed N, Coyte PC, Rampersaud YR. Comparison of lifetime incremental cost: utility ratios of surgery relative to failed medical management for the treatment of hip, knee and spine osteoarthritis modelled using 2-year postsurgical values. Can J Surg. 2012;55:181-90.

56. Ministerio de Sanidad Servicios Sociales e Igualdad. Encuesta Nacional de Salud. España 2011/12. Calidad de vida relacionada con la salud en adultos: EQ-5D-5L [Internet]. Madrid: Ministerio de Sanidad, Servicios Sociales e Igualdad; 2014. Available from: https://www.mscbs.gob.es/estadEstudios/ estadisticas/encuestaNacional/encuestaNac2011/informesMonograficos/ CVRS_adultos_EQ_5D_5L.pdf. [2019 October 23].

57. Janssen MF, Bonsel GJ, Luo N. Is EQ-5D-5L better than EQ-5D-3L? A headto-head comparison of descriptive systems and value sets from seven countries. Pharmacoeconomics. 2018;36:675-97.

58. Buchholz I, Janssen MF, Kohlmann T, Feng Y-S. A systematic review of studies comparing the measurement properties of the three-level and fivelevel versions of the EQ-5D. Pharmacoeconomics. 2018;36:645-61.
59. Wolowacz SE, Briggs A, Belozeroff V, Clarke P, Doward L, Goeree R, et al. Estimating health-state utility for economic models in clinical studies: an ISPOR good research practices task force report. Value Health. 2016;19:704-19.

60. Prodinger B, Taylor P. Improving quality of care through patient-reported outcome measures (PROMs): expert interviews using the NHS PROMs Programme and the Swedish quality registers for knee and hip arthroplasty as examples. BMC health Serv res. BMC Health Serv Res. 2018;18:1-13.

61. Nwachukwu BU, Bozic KJ, Schairer WW, Bernstein JL, Jevsevar DS, Marx RG, et al. Current status of cost utility analyses in Total joint Arthroplasty: a systematic review. Clin Orthop Relat Res. 2015;473:1815-27.

\section{Publisher's Note}

Springer Nature remains neutral with regard to jurisdictional claims in published maps and institutional affiliations.
Ready to submit your research? Choose BMC and benefit from:

- fast, convenient online submission

- thorough peer review by experienced researchers in your field

- rapid publication on acceptance

- support for research data, including large and complex data types

- gold Open Access which fosters wider collaboration and increased citations

- maximum visibility for your research: over $100 \mathrm{M}$ website views per year

At BMC, research is always in progress.

Learn more biomedcentral.com/submissions 